\title{
Oxypetalum laciniatum, uma espécie nova de Asclepiadoideae (Apocynaceae) do sul da Bahia, Brasil
}

Oxypetalum laciniatum, a new species of Asclepiadoideae (Apocynaceae) from southern Bahia, Brazil

\author{
Alessandro Rapini ${ }^{1} \&$ Maria Ana Farinaccio ${ }^{2}$
}

\begin{abstract}
Resumo
Uma nova espécie de Oxypetalum, O. laciniatum Rapini \& Farinaccio, é descrita e ilustrada. Ela foi coletada apenas uma vez, em mata higrófila, no sul do estado da Bahia, e pertence ao complexo O. cordifolium (Vent.) Schltr. Diferencia-se prontamente das demais espécies desse grupo pelas flores com lacínias da corola mais longas (ca. 2,85 cm compr.), polínios mais curtos (até $0,3 \mathrm{~mm}$ compr., cerca de um terço do comprimento do retináculo) e apêndice do ginostégio com ápice levemente bifurcado em ramos subparalelos.

Palavras-chave: Asclepiadaceae, florística, Mata Atlântica, taxonomia.
\end{abstract}

\begin{abstract}
A new species of Oxypetalum, O. laciniatum Rapini \& Farinaccio, is described and illustrated. It was collected only once in the moist forest of southern Bahia, and belongs to the O. cordifolium (Vent.) Schltr. species complex. The new species, however, can be promptly distinguished from the others in this group by the flowers with longer lacinia (ca. $2.85 \mathrm{~cm}$ long), shorter pollinia (up to $0.3 \mathrm{~mm}$ long; about $1 / 3$ of the corpusculum length), and appendix of gynostegium with apex slightly bifid in subparallel branches.

Key words: Asclepiadaceae, Atlantic forest, floristics, taxonomy.
\end{abstract}

\section{Introdução}

Oxypetalum R. Br. (Apocynaceae) é um gênero neotropical com cerca de 120 espécies, ocorrendo da Argentina ao México, mas com centro de diversidade na porção centro-leste da América do Sul (Farinaccio 2006). A maioria das espécies possui flores vistosas, geralmente com ginostégio rostrado, simulando um estigma, e polinários com caudículos horizontais providos de um dente incluso. As espécies brasileiras foram revisadas por Hoehne (1916) e as argentinas por Meyer (1943); desde então, vários estudos têm contribuído para a taxonomia do gênero, com destaque para floras estaduais recentes nas Regiões Sul e Sudeste do Brasil (e.g., Farinaccio 2004; Fontella-Pereira et al. 2004; Schwarz 2006; Marquete et al. 2007).

Durante a preparação da flora de Apocynaceae do estado da Bahia, uma nova espécie de
Oxypetalum foi reconhecida. Ela pertence a o complexo O. cordifolium (Vent.) Schltr., caracterizado pelo hábito volúvel, folhas membranáceas, profundamente cordadas a auriculadas na base, inflorescências laxas e flores frequentemente longipediceladas, com lacínias da corola longas, patentes, e polinários com retináculo laminar. Além de $O$. cordifolium, este complexo inclui também $O$. harleyi (Fontella \& Goyder) Farinaccio, O. mexiae Malme, O. pedicellatum Decne. e O. subriparium Malme. As diferenças entre essas espécies foram consideradas inconsistentes por Fontella-Pereira et al. (2005). Todavia, eles não deixaram de indicar taxonomicamente a correlação entre a morfologia e a distribuição geográfica desses táxons, tratando-os, porém, como subespécies de $O$. cordifolium (para identificação desses táxons, veja chave em Fontella-Pereira et al. 2005).

\footnotetext{
'Universidade Estadual de Feira de Santana, Depto. Ciências Biológicas, Av. Cidade Universitária s/n, Novo Horizonte, 44036-900, Feira de Santana, BA, Brasil. rapinibot@yahoo.com.br
}

${ }^{2}$ Universidade de São Paulo, Depto. Botânica, R. do Matão 277, 5508-970, São Paulo, SP, Brasil. mafarinaccio@hotmail.com 
O conceito amplo de Oxypetalum cordifolium (sensu Fontella-Pereira et al. 2005) apenas transfere a dificuldade na separação dos táxons e a suposta inconsistência entre seus caracteres para o nível infraespecífico. Assim, tem-se preferido (e.g. Rapini \& Farinaccio 2008) mantê-los no nível de espécie até que dados objetivos sobre a relação entre eles sejam apresentados. Nesse sentido, adiciona-se aqui mais uma espécie a este complexo: $O$. laciniatum Rapini \& Farinaccio. Ela pode ser facilmente reconhecida pelas folhas velutinas e subcordadas na base, flores longipediceladas, com corola verde-escura, de lacínias longas (ca. 2,85 cm compr.) e divergentes, polínios curtos (menos de um terço do tamanho do retináculo) e apêndice do ginostégio com ápice bífido em ramos subparalelos.

\section{Material e Métodos}

Nos últimos 15 anos, foram examinadas as coleções de Oxypetalum depositadas nos principais herbários da América Latina, Estados Unidos e Europa: ALCB, AMAZ, AS, ASE, B, BA, BAB, BHCB, BM, BOTU, BR, C, CAS, CEPEC, CESJ, CORD, CR, CTES, CUZ, EAC, ENCB, ESA, F, FCQ, G, GH, HAL, HAS, HB, HOXA, HPL, HRB, HRCB, HST, HUEFS, HUFU, HUT, HXBH, IAN, IEB, INPA, IPA, JPB, K, LE, LIL, LPB, M, MAC, MBM, MBML, MCNS, MG, MO, MOSS, NY, OUPR, P, PACA, PY, R, RB, S, SI, SJRP, SMU, SP, SPF, SPSF, ST, TEPB, UB, UC, UEC, UFMA, UFP, UFRN, UFRPE, UNBA, UPCB, URGS, US, USM, USZ, VEN, VIC, VT, W, WIS, WU e XAL (siglas conforme Thiers 2010). A terminologia utilizada na descrição morfológica está baseada em Radford et al. (1974) e Stearn (1998). As medidas e ilustrações de detalhes florais foram realizadas com auxílio de microscópio estereoscópico Leica MZ8, com câmara clara acoplada.

\section{Resultados e Discussão}

Oxypetalum laciniatum Rapini \& Farinaccio, $s p$. nov. Tipo: BRASIL. BAHIA: Wenceslau Guimarães, Estação Ecológica Estadual Nova Esperança, margem da cachoeira do Rio Serra Grande, $13^{\circ} 35^{\prime} 43^{\prime \prime} S$, 3943'18'W, 27.VII.2001, fl., L.A. Mattos-Silva, S.C. Santana \& J.L. Paixão 4493 (holótipo HUEFS!; isótipos ALCB!, CEPEC!).

Fig. 1

Oxypetalo pedicellato Decne. affine, a quo lobis corollae longioribus (circa 2,85 mm vice usque $2 \mathrm{~cm}$ longis), polliniis brevioribus (circa $0,3 \mathrm{~mm}$ vice 0,5 $\mathrm{mm}$ longis vel longioribus) et appendice gynostegii in ramos subparallelos leviter bifido (vice in ramos divaricatos profunde bifido) differt.

Trepadeira; ramos pubescentes a hirsutos; látex alvo. Pecíolo 0,7-2 cm compr., hirsuto; lâmina foliar elíptica, subcordada na base, acuminada no ápice, velutina em ambas as faces, 6-10 × 2,5-3,5 $\mathrm{cm}$, membranácea, com 2 pares de coléteres na base da face adaxial. Monocásios 3- ou 4-floras; pedúnculo 1-3 mm compr.; pedicelos 4-4,5 cm compr. Cálice abaxialmente hirtelo; sépalas estreitamente lanceoladas, ca. 3,2 $\times 0,7 \mathrm{~mm}$; 1 ou 2 coléteres alternissépalos, digitiformes, ca. $0,34 \times$ $0,13 \mathrm{~mm}$. Corola verde-escura, rotácea, abaxialmente hirtela, mais esparsamente para o ápice, adaxialmente serícea no tubo, glabra no restante; tubo ca. $2 \times 2,7$ $\mathrm{mm}$; lacínias subuladas, ca. $28,5 \times 2,6 \mathrm{~mm}$, patentes. Corona pentalobada; lobos $1,5-1,7 \times$ ca. $1,2 \mathrm{~mm}$, largamente oblongos, carnosos, mais espessos no ápice e nas margens, abaxialmente levemente apiculado. Anteras ca. 2 mm compr.; apêndice membranáceo suboblongo, revoluto para a base. Retináculo linear, ca. 1,03 × 0,13 mm; caudículos com dente córneo distalmente, ca. 0,1 mm compr.; polínios oblongos, 0,28-0,3 ×0,08-0,09 mm. Apêndice do ginostégio rostrado; rostro ca. $4,5 \mathrm{~mm}$ compr., ca. $1 \mathrm{~mm}$ bífido em ramos subparalelos entre si.

Oxypetalum laciniatum foi coletada uma única vez, em mata higrófila sobre solo argiloso, no sul da Bahia, apresentando flores em julho. É facilmente reconhecida dentre as espécies da Bahia pelos pedicelos longos e delgados partindo de um pedúnculo curto, semelhantes aos encontrados em O. pedicellatum. As lacínias da corola são as mais longas dentre as espécies brasileiras do complexo $O$. cordifolium (nas demais espécies, elas não ultrapassam $2 \mathrm{~cm}$ compr.), enquanto os polínios são os mais curtos $(0,3$ vs. $0,5 \mathrm{~mm}$ ou mais, nas outras espécies), correspondendo a menos de um terço do comprimento do retináculo (vs. pelo menos cerca de metade); o ápice do ginostégio é levemente partido, mas com os ramos subparalelos, enquanto nas demais espécies do grupo essa divisão costuma ser profunda, geralmente quase até a metade, e os ramos são divergentes entre si.

\section{Agradecimentos}

Este trabalho faz parte do Projeto de Pesquisa em diversidade e filogenia de Apocynaceae apoiado pela Fapesb. Agradecemos ao Dr. Cássio van den Berg as correções na diagnose em latim. $\mathrm{O}$ primeiro autor é bolsista PQ-2 do CNPq. 


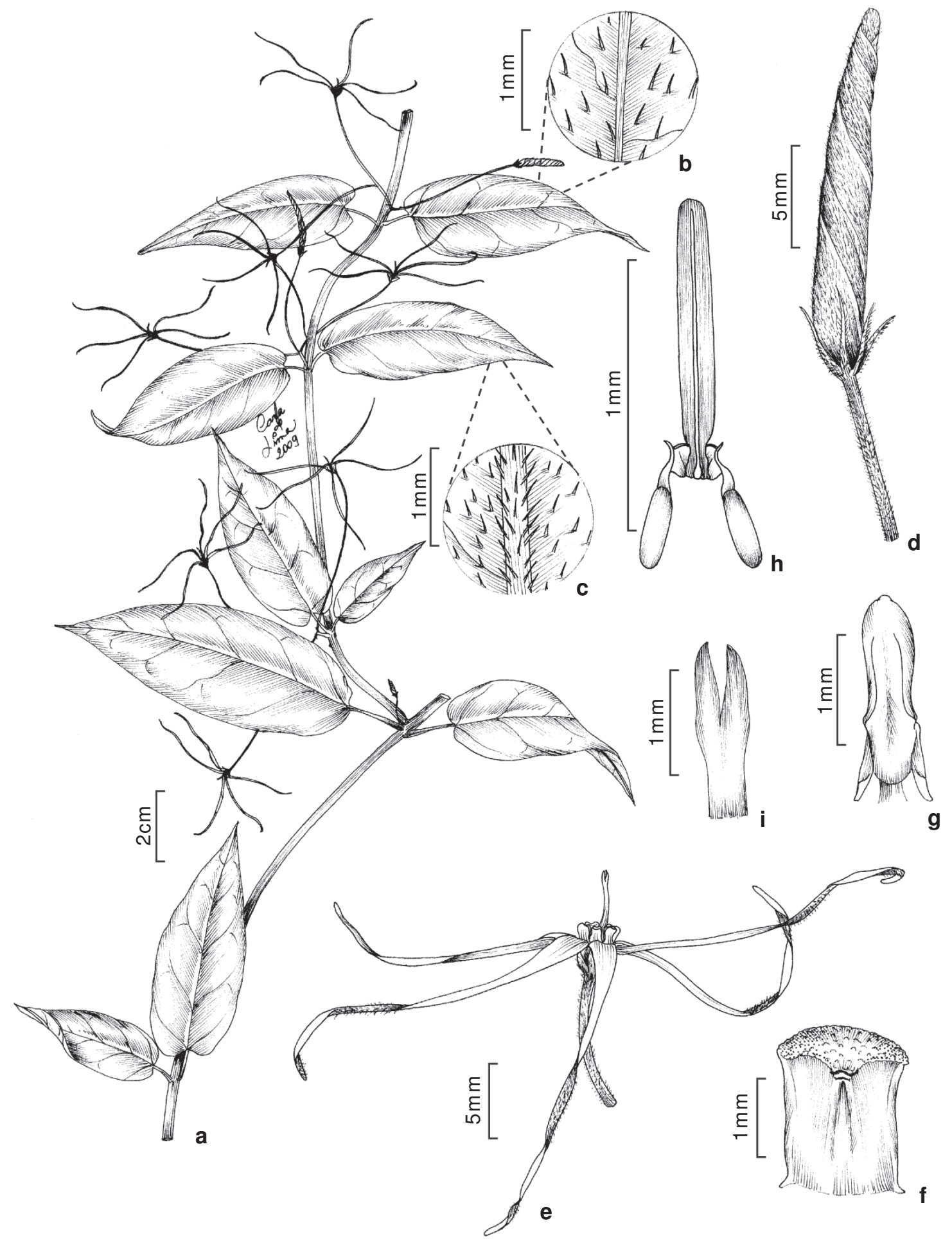

Figura 1 - Oxypetalum laciniatum Rapini \& Farinaccio - a. ramo com flores; b. detalhe do indumento da face adaxial da folha; c. detalhe do indumento da face abaxial da folha; d. botão floral; e. flor; f. lobo da corona, face adaxial; g. estame; h. polinário; i. ápice do apêndice do ginostégio (Mattos-Silva et al. 4493).

Figure 1 - Oxypetalum laciniatum Rapini \& Farinaccio - a. branch with flowers; b. detail of indumentum on the adaxial surface of leave; c. detail of indumentum on the abaxial surface of leave; d. flower-bud; e. flower; f. corolla lobe, adaxial surface; g. stamen; h. pollinarium; i. apex of the gynostegium appendix (Mattos-Silva et al. 4493). 


\section{Referências}

Farinaccio, M.A. 2004. Oxypetalum R.Br. In: Wanderley, M.G.L.; Shepherd, G.L.; Melhem, T.S. \& Giulietti, A.M. (ed.). Flora fanerogâmica do estado de São Paulo. Instituto de Botânica, São Paulo. Vol. 4. Pp. 130-150.

Farinaccio, M.A. 2006. Sistemática molecular de Oxypetalum R.Br. (Apocynaceae, Asclepiadoideae). Tese de Doutorado. Universidade de São Paulo, São Paulo. 142p. + anexos.

Fontella-Pereira, J.; Valente, M.C.; Marquete, N.M.S. \& Ichaso, C.L.F. 2004. Apocináceas-Asclepiadóideas. In: Reis, A. (ed.). Flora ilustrada catarinense. Herbário Barbosa Rodrigues, Itajaí. 250p.

Fontella-Pereira, J.; Goyder, D.J. \& Marquete, N.F.S. 2005. Infraspecific variation in Oxypetalum cordifolium (Vent.) Schltr. (Apocynaceae: Asclepiadoideae). Kew Bulletin 60: 103-109.

Hoehne, F.C. 1916. Monografia das Asclepiadaceas brasileiras. (Monographia Asclepiadacearum Brasiliensium). Oxypetalum et Calostigma. Commissão de Linhas Telegraphicas Estrategicas de Matto-Grosso ao Amazonas 38(1): 1-131, tabs. 1-59; ib. (1) supl.: 1-13, tabs. 60-62; ib. (2): 1-29, tabs. $1-12$
Marquete, N.F.S.; Fontella-Pereira, J. \& Valente, M.C. 2007. Asclepiadoideae (Apocynaceae) from southeastern Brazil. I. The genus Oxypetalum from Rio de Janeiro State, Brazil. Annals of the Missouri Botanical Garden 94: 435-462.

Meyer, T. 1943. Revisón de las especies argentinas dél género "Oxypetalum" (Asclepiadaceae). Lilloa 9: 5-72.

Radford, A.E.; Dickison, W.C.; Massey, J.R. \& Bell, C.R. 1974. Vascular plant systematics. Harper \& Row, New York. 891p.

Rapini, A. \& Farinaccio, M.A. 2008. Two taxonomic changes in Asclepiadoideae (Apocynaceae) from Brazil. Neodiversity 3: 19-21.

Schwarz, E.A. 2006. O gênero Oxypetalum R.Br. (Apocynaceae, Asclepiadoideae) no estado do Paraná. Tese de Doutorado. Universidade Estadual Paulista, Rio Claro. 227p.

Stearn, W.T. 1998. Botanical Latin. 4 ed. Timber Press, Portland. 546p.

Thiers, B. 2010. Index Herbariorum: A global directory of public herbaria and associated staff. New York Botanical Garden's Virtual Herbarium. Disponível em <http://sweetgum. nybg.org/ih/>. Acesso em 13 abril 2010. 